\title{
Dossiê
}

Resumo

Este artigo discute algumas questões decorrentes do filme documentário "O nome dela é Sabine (Elle s'appelle Sabine)", dirigido por Sandrine Bonnaire (França/2007). O filme apresenta um registro sobre opercurso de Sabine, irmã de Sandrine, que passon por um periodo de cinco anos de internação em hospital psiquiátrico. Recortando cenas de filmagens familiares e de imagens da irmã captadas nos anos de 2006 e 2007, Sandrine nos apresenta uma narrativa que permite indagar questões que atravessam a experiência dos sujeitos nas instituições e que far. emergirpontos relevantes sobre os efeitos subjetivos dos laços que se estabelecem na fratria.

Descritores: transmissão; $d u$ plo; transitivismo; educacional; instituição.

\section{ELA SE CHAMA SABINE...}

\author{
Angela Vorcaro \\ Mônica Rahme
}

\section{Introdução}<smiles>c1ccccc1</smiles>

filme O nome dela é Sabine' (Elle s'appelle Sabine), da atriz e diretora francesa Sandrine Bonnaire, aborda momentos anteriores e posteriores à internação de sua irmã, Sabine Bonnaire, no hospital psiquiátrico. Sabine tem aproximadamente 28 anos de idade na época e é internada na unidade de doentes considerados difíceis do hospital

Psicanalista. Doutora em Psicologia Clínica pela Pontifícia Universidade Católica de São Paulo e professora adjunta do Departamento de Psicologia da Universidade Federal de Minas Gerais (UFMG), Belo Horizonte, MG, Brasil.

- Doutora em Educação pela Faculdade de Educação da Universidade de São Paulo e professora do Departamento de Educação do Instituto de Ciências Humanas e Sociais da Universidade Federal de Ouro Preto ((ICHS/UFOP), Mariana, MG, Brasil. 
psiquiátrico Paul-Guiraud, em Villejuif, e no Hospital Murets, onde é diagnosticado um quadro de Psicoinfantil com comportamentos autísticos.

O filme entremeia cenas do período anterior à internação, provenientes de filmagens familiares e de registros realizados pela própria Sandrine, bem como de imagens produzidas no percurso posterior à internação, captadas entre os anos de 2006 e 2007, em uma residência terapêutica (centre d'accuei) onde Sabine passa a viver na época, em Charente.

Essas filmagens compreendem um período de aproximadamente 25 anos da vida de Sabine contada por Sandrine. É ela quem seleciona o que podemos ver e saber dessa história: os trechos dos vídeos familiares, os momentos vividos com a irmã nos passeios e viagens, quem produz a voz que escutamos em alguns momentos da película, narrando a trajetória de Sabine. A filmagem permite supor que a proximidade de convivência experimentada na infância - Sabine é um ano mais nova que Sandrine - teria produzido esse desejo de dar visibilidade, de documentar e apresentar ao público a história da irmã.

Quando o documentário se inicia, a primeira imagem que vemos é a de Sabine adolescente: seus cabelos são longos, o olhar dirigindo-se frequentemente para a câmera, o corpo semelhante ao de outras adolescentes. Há charme nos seus gestos e movimentos. Em seguida, o documentário exibe uma filmagem de Sabine na residência terapêutica, tendo em torno de 38 anos. Seus movimentos são lentos, os cabelos cortados bem curtos, a boca quase sempre aberta, o corpo expressivamente fatigado.

Segundo o que nos indica a narrativa de Sandrine, na infância Sabine apresentava comportamentos diferenciados dos irmãos, tendo sido matriculada pelos pais em uma escola para "crianças anormais", na qual aprendeu a ler e a escrever. Aos 12 anos, seus pais a matriculam na mesma escola que os irmãos. A narradora nos conta que a diferença da irmã é, então, perceptível para os outros alunos, que começam a zombar dela. Sabine passa a se morder e a se bater, tira a roupa no pátio do colégio. Depois disso, ela se desvincula da escolarização formal, mantendo uma vida mais doméstica. Compra livros e estuda piano com um professor particular. Aprende a tocar peças de Bach e Schubert, chegando a compor uma peça para piano.

Anos mais tarde, quando as irmãs e o irmão saem de casa, Sabine passa a morar apenas com a mãe. Nesse período, as irmãs Sandrine e Lydie organizam saídas para ela, e Sabine convence a mãe a deixá-la

252 Estilos clin., São Paulo, v. 18, n. 2, mai./ago. 2013, 251-267. 
ir passear em Paris. Em 1993, tendo em torno de 25 anos de idade, Sabine viaja com Sandrine de Concorde para Nova Iorque, realizando um sonho de Sabine: conhecer a América. Aprender inglês e piano eram duas grandes áreas de interesse de Sabine, que ficam bem registradas pelas filmagens.

Em 1996, com a morte do irmão mais velho, a mãe decide mudarse com Sabine para o interior da França, o que dificulta o encontro sistemático das irmãs. No entendimento de Sandrine, isso provoca um “choque emocional", pois Sabine se sente abandonada e regride. Ela passa a ter comportamentos grosseiros com os outros, sobretudo com a mãe, e destrói tudo que parecia lhe ser mais caro. As irmãs propõem que ela more com elas para ver se as coisas mudam e para dar uma folga à mãe. Contudo, Sabine continua agressiva e as irmãs acabam decidindo levá-la ao hospital psiquiátrico para terem um parecer médico, lá permanecendo por quinze dias. Sai da instituição psiquiátrica sem nenhum diagnóstico preciso. Percebendo que o hospital não seria o local mais indicado para Sabine, as irmãs passam a procurar um centro especializado que pudesse acolhê-la, mas não encontram nenhuma instituição disposta a recebê-la. Alugam, então, um apartamento em frente ao apartamento de Sandrine, mas depois de uns meses o pessoal contratado para cuidar dela desiste da tarefa e Sabine é internada novamente, ficando cinco anos no hospital.
Para Sandrine, no "hospital, as angústias de Sabine se exacerbam": ela se bate, se automutila, bate a cabeça contra a parede. É contida e ingere altas doses de neurolépticos. Sai da internação prostada, 30 quilos mais gorda, não tem quase nenhuma memória. Ela treme e baba. Não sabe mais fazer sua higiene sozinha.

\section{O diagnóstico de autismo}

O diagnóstico de "psico-infantil com comportamentos autísticos"é apresentado à família em um momento posterior à internação no hospital psiquiátrico e deixa muitas interrogações para o espectador quando tomado do ponto de vista psicanalítico. O levantamento do conjunto de comportamentos que Sabine passa a apresentar não seria suficiente nessa perspectiva, assim como não são suficientes os dados que o documentário disponibiliza. Contudo, Laurent (2008) ressalta uma função que esse diagnóstico parece ter adquirido para a família e que merece ser observada:

O significante com o qual Sandrine se pode confrontar, diante da terrível evolução de sua irmã, que funciona na família como um tipo de duplo de si mesma, é pobre, mas suficiente. Sabine é diagnosticada de "psico-infantil, com condutas autísticas".... A passagem de psicose infantil a psico-infantil permite a introdução de um significante novo: Autismo. (Laurent, 2008, pp. 2-3) 
Quando recebida na residência terapêutica, Sabine é diagnosticada como autista e de fato esse significante parece clarear para os outros os sentidos de seus comportamentos. Como relata sua médica, Sabine chega à residência muito fechada em si mesma, desconfiada em relação aos outros, angustiada e com episódios de mutismo.

Desde a sua ida para a escola comum, Sabine tem momentos nos quais se manifesta ativamente agressiva e potencialmente destrutiva de tudo o que lhe faz borda, aí incluindo seus queridos parentes, seus amados brinquedos e, ainda, a si mesma. Assim, na residência terapêutica, ela "protege de seu próprio furor os poucos objetos que lhe restam (bonecos, jogos), fechando-os em uma rede de vime. Também pede que a tranquem - a ela mesma - para dormir. Ela é a boneca fechada na rede" (Laurent, 2008, p. 3).

Os notáveis efeitos de uma degradação debilizante demonstram que, se houve alguma vez uma produção delirante, ela se perdeu enquanto função de trabalho psíquico. A condição de inércia de Sabine, que lhe é prevalente, como testemunhamos a partir do filme, parece poder ser atribuída aos fracassos das suas tentativas de inserção social, além das perdas de convívio familiar, da iatrogenia das hospitalizações e da medicação.

Sem nuances expressivas, com um corte de cabelo que o mantém rente à cabeça, retirando-lhe qualquer indício de diferença sexual, torna-se portadora de um físico que condena qualquer gesto singular submetido a seu corpo-monolito. A perda da prosódia deixa a voz sem alcance ou modulação. Assim, ao reconhecer-se nas filmagens da própria infância, emite um grito opaco, contido. Ela terá sido - mas não é mais. Entretanto, sem endereçar seu "grito para" alguém, mas com seu "puro grito" (Vivès, 2012) ou sustentando apelos pronunciados educadamente, tenta aderir-se à irmã.

\section{A educação de Sabine}

Embora o filme estabeleça o hospital psiquiátrico como marco divisório entre duas condições subjetivas distintas, ao enfatizar mais diretamente o que é anterior e posterior à passagem de Sabine pelo manicômio, é interessante destacar o que é brevemente narrado a propósito de sua inserção escolar. Sandrine nos conta que Sabine frequentou uma escola especializada, na qual aprendeu a ler e a escrever, e que sua entrada na escola comum - não em qualquer escola comum, mas naquela para onde tinham ido também seus irmãos - foi uma experiência aterrorizante para a irmã, a partir da qual nenhuma outra escola se tornou possível em sua adolescência. A voracidade e a exacerbação dos colegas diante da diferença apresentada por Sabine pode ser resumida na frase 
"Sabine, a louca". O que se passa na escola lhe é insuportável a ponto de produzir nela movimentos de autoagressão e de total descontrole. Do que sabemos de Sabine, a escola comum parece presentificar as bordas de um discurso social que não suporta a diferença.

Esse pequeno recorte que escutamos de uma única narrativa, e que certamente mereceria ser recheado de outros elementos, é interessante para nos fazer estranhar o que muitas vezes banalizamos em termos da presença da diferença na escola. Se há crianças que se identificam a um outro que incorpora algo em torno da diferença e dele se aproximam, para outras crianças esse encontro desperta o insuportável, e, nesse momento, tornar o diferente um objeto de gozo parece ser um destino não raro. E nessa quase horda selvagem há uma expectativa de que o adulto intervenha, não figurando como mais um espectador.

A tentativa da família Bonnaire de ter os filhos estudando em uma única escola parece estar sintonizada com os rumos que a política educacional francesa começa a adotar a partir do final dos anos 1960 e início dos anos 1970. Nesse momento, as instituições destinadas às crianças consideradas inadaptadas ou anormais passam a ser mais pontualmente questionadas (Plaisance, 2000). Uma forte expressão disso é a lei de 30 de junho 1975 em favor das pessoas com deficiência, que mantém os sistemas geral e especial a serviço da obrigatoriedade escolar, delineando como misto o sistema francês de integração. A lei de 1975 orienta que a educação especial pode acontecer nos meios da educação comum ou nos estabelecimentos e serviços especializados, constituindo-se como alternativa à educação comum.

Em que pese a dimensão geracional presente no percurso escolar de Sabine, pois era a escola integradora e não a inclusiva que circulava no contexto de sua adolescência, é na escola especial que ela aprende a ler e a escrever, e é esse o espaço que parece ter sido menos invasivo para ela. Tal fato não sustentaria uma apologia à escola especializada, modalidade escolar que pôde ser amplamente debatida em face dos processos de exclusão e segregação por ela gerados, mas indica o quanto questões do sujeito podem escapar ao que se avalia como mais promissor institucionalmente.

Entretanto, o educacional não se restringe de modo algum ao escolar no caso de Sabine. Além do que ela aprende em casa após sua passagem pela escola comum, e o educacional em seu viés de aprendiragem encontra-se presente também nas atividades desenvolvidas 
na residência terapêutica. Sabine é convidada pelos educadores a participar das atividades orientadas de jardinagem e de cuidado dos animais. Sabine acompanha essas atividades institucionais, e as cenas nos transmitem o esforço que ela parece estar fazendo para realizar o que seria o mínimo, em uma espécie de adaptação à vida para sobreviver, como bem ressalta sua médica, em um dos depoimentos documentados.

As Atividades de Vida Diária e de Vida Prática, conhecidas como AVDs e AVPs, marcaram e marcam a rotina de muitas instituições especializadas, como uma forma de tornar os sujeitos mais ativos e de trabalhar sua autonomia. Mas podem facilmente se tornar uma simulação bastante artificial de uma vida comunitária, na qual o coletivo está completamente submetido ao anonimato, como algumas cenas do filme deixam transparecer. Nesse caso, ao invés de autonomia, é uma debilização do sujeito que emerge, repetindo movimentos e sequências de ações. Essas cenas contrastam com a espontaneidade de Sabine na piscina pública, quando brinca e joga com a educadora que a acompanha.

\section{público de Sandrine}

O que mobilizaria Sandrine ao propósito de tornar pública a virulência de um fracasso familiar, escolar, hospitalar e social nos cuidados de sua irmã?

Para esboçar uma resposta, não poderemos prescindir do que Charcot inaugura e que Freud recolhe. Fazendo vigorar a cena hospitalar da présentation des malades sobre a cena do mundo, Charcot distinguiu doentes que se faziam protagonistas de um tratamento público, mas situou especialmente o efeito do doente que, ao mostrarse, promovia um modo de tratamento do público. Assim, Charcot instituiu o tratamento do público pelas lições de singularidade que o paciente ensina, solapando o saber instituído. Dessa experiência, o espectador Freud (1892/1977a) nos lembra a formulação de Charcot ao responder-lhe sobre um caso que se contrapunha a uma teoria vigente: "La théorie est bon; mais ça n'enpêche pas d'existir'. Se ao menos se soubesse o que é que existe" (p. 198). Segundo a letra de Freud (1925/1977d), esse episódio deixou "indelével marca em meu espírito” (p. 24). Assim, Freud localizou o efeito das apresentações 
públicas de Charcot, das quais saia "com o espírito saturado como na saída de um teatro", como revelou em uma correspondência (citado por Dorey, 1996). Tendo recolhido daí um ensinamento de método, Freud (1905/1977c) localizou alguns mecanismos que instigam o ato de tornar público um saber não sabido que se lança na expectativa de reconhecimento, sendo, portanto, dependente das ressonâncias causadas sobre a terceira pessoa (o Publikum), não para explicar seu suposto conteúdo até então desconhecido, mas para partilhar seus efeitos e assim efetuar laço social. São, portanto, os efeitos provocados que definem se uma transmissão terá ocorrido. A função do público, essa terceira pessoa que sanciona um dito é também ressaltada por Freud (1906/1977d) ao remeter-se à origem do teatro nos ritos sacrificiais (já desenvolvida em "Totem e tabu") e à sua conhecida finalidade desde Aristóteles: aquela de despertar o "terror e a piedade" para "purgar as emoções". Assim, permitem ao espectador "expelir vapor" livrando-se de suas próprias emoções enquanto abre fontes de fruição (p. 321). Quando tais circunstâncias estão presentes, mesmo a derrota serve à satisfação masoquista. Como na ilusão propiciada pelo jogo, o espectador identifica-se a um herói, dando livre vazão a seus impulsos, com a vantagem de ser poupado do que há de árduo na experiência concreta, prenhe de sofrimentos e riscos que poderiam não apenas anular o prazer, mas também a própria vida.

Não é difícil elencar as várias razões que teriam promovido o ato de compartilhar tanto o enigma de Sabine quanto o modo de tratá-lo: sensibilizar o espectador quanto aos percalços que experimentam os sujeitos considerados diferentes e suas famílias, esclarecer as lacunas presentes nas políticas públicas e alertar para a possibilidade de visão crítica diante da existência de diferentes terapêuticas. Afinal, ao contrário do que encontramos até mesmo no relato sobre o menino selvagem, Victor de Aveyron (Itard, $1801 / 2000$ ), que tendo crescido na floresta se identificava mais aos animais do que aos humanos e que aprende alguns comportamentos considerados sociais pela via educacional, a passagem de Sabine pelo hospital psiquiátrico parece evidenciar os danos de um caminho contrário em que o acolhimento que recebe é sua pacificação com neurolépticos à custa de extrair, dela, algumas bordas que permitiam o laço social anteriormente estabelecido.

Com motivos insondáveis, Sandrine aposta em efeitos do filme sobre os espectadores, tornando o percurso de Sabine transmissível. 
Efetivamente, essa diretora-irmã evidencia a tensão permanente no tratamento do sujeito em grave sofrimento psíquico, explicitando a tração entre os polos da impossibilidade e da impotência em todos os seus sucessivos âmbitos: seja do campo familiar, social e das políticas de saúde.

É contundente o horror do adestramento social que delimita Sabine, morosamente, sem nada se dispor a partilhar nem a trocar, sustentando-se em uma inércia da qual nada a instiga a abandonar, a despeito dos esforços patentes da equipe de acompanhantes da residência terapêutica em que ela vive. Desse ângulo, pode-se constatar que, enquanto a ausência de investimento do autista no discurso nos constrange a reconhecer que o Outro pode nos faltar (Vorcaro \& Rahme, 2011), Sabine explicita como a perda da singularidade pode incidir sobre um sujeito a ponto de este constringirse exclusivamente a um ser mais ou menos adestrado, fazendo coincidir seuenunciado à sua presença, impossibilitado de sustentar qualquer cena enunciativa.

Assim, o efeito do filme sobre Scarlett e Philippe Reliquet (2011), que também compartilham em livro episódios de sua convivência com a filha Garance, diagnosticada como autista, é o de sublinhar que o filme pode produzir no espectador o "efeito de uma terapia violenta", pois suas imagens são difíceis de suportar e o destino de Sabine, trágico. Ao mesmo tempo, o filme lhes instiga a se 
perguntarem pelo que poderia ter sido evitado dessa tragédia, retomando seus esforços para que Garance não tenha os mesmos destinos que Sabine: "No caso de Garance, nós redobramos nossos esforços para preservar suas qualidades sensíveis, conservar um físico charmoso, desenvolver suas aptidões" (Reliquet \& Reliquet, 2011, p. 32).

Com essa perspectiva, reencontramos nesse filme, a exemplo de outros relatos que transformaram partes da experiência em uma obra dirigida ao público, a necessidade de divulgar uma experiência estabelecida em âmbito privado. Nos termos em que Faivre-Jussiaux (1995) justifica seu livro relativo ao tratamento de Nathanaël:

que a loucura de Nathanaël mantenha-se legível, e assim o humanize, é ao mesmo tempo o desejo do analista e a aposta do escritor... Se fracassar em minha tarefa, se meu leitor não consegue nos seguir, nós restaremos, meu paciente e eu, fora do discurso. Eu me junto então a Nathanaël em seu enclausuramento, e de uma certa maneira eu o traio. É o único risco verdadeiro que eu corro ao escrever este livro. (pp. 15-16)

Enfim, esse filme parece requerer, da diretora-irmã Sandrine, um processo de elaboração subjetiva que implica e depende do ato de tornar público seu lugar nisso que, até então, apenas as duas partilham. Dessa perspectiva, buscar-se-ia uma modalidade de tratamento público do problema, para assim tentar tratar o que perturba, dissolvendo o mais íntimo e mais desconhecido nó. A inclusão do depoimento da mãe de Olivier, outro morador da mesma residência terapêutica onde Sabine resiste, permite supor alguma reverberação de Sandrine no testemunho recolhido: registrar os traços daquilo que escapa ao entendimento, reconhecer dores e culpas que ultrapassam uma racionalidade suposta.

Entretanto, resta ainda abordar o que nos parece mais importante. Talvez sem querer, Sandrine parece apostar na transmissão do lugar fraterno que ocupa e que permite fazer incidir, ao menos, alguma singularidade de sua irmã, mesmo que essa singularidade só possa ser distinguida ao espectador pela intermediação de sua câmera.

A essa convocação de que façamos laço com o mostrado, que num só tempo deixa ver Sabine descoberta pela incidência provocativa de Sandrine, inicialmente só podemos nos aproximar por meio de uma escolha forçada. Sem nada deixar capturar 
de uma enunciação própria, Sabine se deixa ver registrada por Sandrine, que assim estabelece uma posição de interface entre Sabine e os espectadores. Estes podem conhecê-la na identificação proposta por Sandrine, a partir de ressonâncias que fisga dela, transitivando-a. Como nos localizar diante do que nos destitui de qualquer posição antecipável pelo discurso que não seja o da câmera de Sandrine? Essa insistência persistente do que não distinguimos nos conduz ao único recurso passível de assimilar algo e do qual, longe de nos furtarmos, pretendemos dele nos servir.

Há uma cena que nos permite localizar algo que nos importa aqui. Trata-se da cena de seu passeio a uma lanchonete chamada Quick: diante de sua imagem refletida no espelho, Sabine comenta com Gladys, a profissional que atua na residência e que a acompanha nesse passeio: "Eu achei que tivesse um hambúrguer só, mas na verdade eu tenho dois. Esse de lá [que se encontra refletido no espelho] e esse aqu?".

Esse modo de lidar com o efeito especular considerando a imagem refletida como realidade mostra que não se trata de uma ausência de espelhamento, mas de uma imagem refletida que funciona como uma extensão de si mesma. Tal multiplicação de hambúrgueres diz algo da duplicação dos eus de Sabine, que pode ser elucidativa para pensar no quanto Sandrine faz função de seu duplo.

Sabine sustenta sistematicamente a estrutura dialógica com sua irmã por meio de uma mesma resposta às convocações feitas por Sandrine. Nesses casos, em seu turno dialógico, Sabine ocupa a cena enunciativa respondendo, sem no entanto abordar o tema da interrogação que lhe é feita. Assim, em resposta à irmã, ela interpõe um pedido que protela indefinidamente a resposta à convocação, mas sua questão não é qualquer. É sempre relativa a um apelo para garantir a continuidade da presença de Sandrine, consigo, deixando nítido o efeito de lacuna da separação da irmã e a consequente reivindicação pela permanência desta ali, que chega a uma insistência insuperável: Sabine não pode interagir com a irmã por estar ocupada em se precaver que esta não lhe falte. Esta função da presença física concreta de elementos norteadores do sujeito pode ser talvez assimilada ao que Freud (1900/1977b), ao distinguir os mecanismos dos sonhos, nomeou como "condições de figurabilidade" 2 tão evidentes na representação do brincar próprio à criança, que não pode prescindir de elementos correlativos dispostos no seu cenário lúdico para figurar sua realidade psíquica (Vorcaro \& Veras, 2008).

Assim, esclarecendo que na psicose o inconsciente se encontra “articulado à flor da terra" (p. 21) ou “a descoberto" (p. 73), Lacan (1988) também nos permite desdobrar a modalidade pela qual, nessa condição, o sujeito se relaciona com a linguagem. Lacan (1988) enfatiza que a maneira do sujeito sofrer o fenômeno do discurso 
pode revelar uma dimensão constitutiva. Essa dimensão é a distância entre $\mathrm{o}$ vivido psíquico e a situação semiexterna em que, em relação a todo fenômeno da linguagem, se acha qualquer sujeito. A origem do eu implica a elipse de seu ser em prol da imagem em que ele se reflete sob o nome de eu. Entre essa imagem do eu e a imagem do Outro se instaura a dupla perspectiva no interior do sujeito entre eu e ideal do $e u$. Entretanto, quando acontece de o sujeito perder ou não conseguir esse Outro (lugar estrutural da linguagem que lhe permite supor uma medida orientadora), ele encontra o outro puramente imaginário que o captura duplicando seus atos (Lacan, 1988, p. 238). Podemos supor que Sabine, alheia a tal referente necessariamente implicado na fala de qualquer sujeito, não pode prescindir do semelhante para tentar reconstituir espacialmente a cena de sua realidade psíquica. Assim, a demandada presença de Sandrine não é apelo puramente fraterno, mas também teria, para Sabine, uma função de baliza incorporadora de uma posição estrutural que permite orientar, concretamente, sua subjetividade. Excluído, o Outro é dito pelo outro.

No esquema L, Lacan (1985) traça a linha da fala plena entre o sujeito (S) e o campo do Outro, que é interrompida pelo desvio, por dois eus imaginários, o ego e o outro (seu semelhante). Lacan esclarece que, na psicose, a característica essencial do fenômeno elementar é que o sujeito fala literalmente com o seu eu, ele fala dele, e é como se um 
terceiro, seu substituto de reserva, falasse e comentasse sua atividade (1988, p. 23).

Como estamos no plano do funcionamento do inconsciente à flor da terra, é interessante notar como essas posições podem estar encarnadas. O outro (o semelhante) poderia ser localizado nesse filme como Sandrine, a irmã-Diretora. Entretanto, cabe considerar que o campo do Outro, do discurso organizador e do laço social ( $A$, que, no contexto deste artigo, poderíamos chamar de Publikum em referência à $3^{\mathrm{a}}$ pessoa de Freud) só faz efeito e só tem vigência sobre Sandrine.

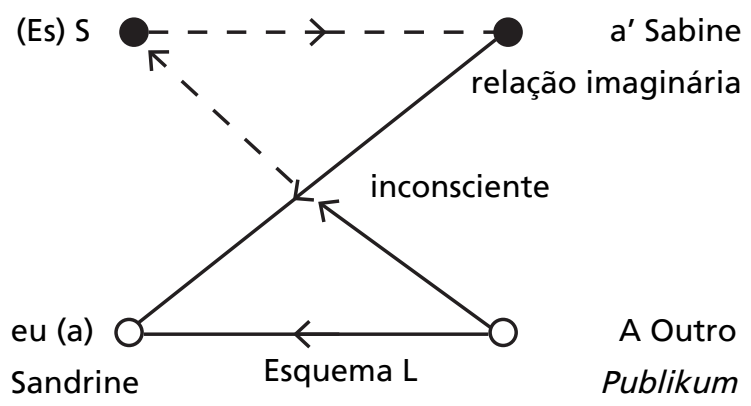

\section{Sandrine e Sabine: uma infância compartilhada}

O filme é atravessado por instantes de interação efetiva entre as irmãs. Assim, Sandrine dirige uma pergunta a Sabine: "O que é o amor para você?". E ela responde: "Isso me faz bem?'. Conta que terá um marido bombeiro, que ela não conhece ainda. Terá dois filhos: Camille e Antoine. "Eu me sinto capaz de cuidar do meu bebê." "Eu não baterei nos meus filhos." Em outro momento, quando se prepara para uma saída, Sabine solicita a Gladys (uma das educadoras): "Vocêpode passarperfume em mim para agradar Sandrine?’ Ao que Gladys responde: "Também é importante você agradar a você mesma". Sabine retruca: "Eu sou bela?' É ao ser filmada por Sandrine que, deitada em seu quarto, Sabine diz: "Você não é uma puta, você é minha irmã. Você não é sacana, você é minha irmä".

No final do filme, Sandrine propõe que Sabine veja cenas filmadas da viagem delas para Nova Iorque. Na primeira tomada, vemos 
apenas Sabine diante da câmera. Ela emite sons opacos, emociona-se e diz algumas frases, como: "Nesse tempo eu morava com mamãe... tinha os cabelos longos". Chora enquanto diz isso e completa: "Isso me faz chorar de alegria". Em uma das cenas exibidas de Sabine adolescente, ela olha na direção do espectador, que é, nesse momento, a própria Sabine: Sabine que olha Sabine. Apenas quando a tomada se amplia, vemos que os colegas da residência terapêutica assistem com ela.

O documentário termina com uma imagem de Sabine rindo na direção à câmera, em um movimento muito parecido com os que tínhamos visto nas filmagens antigas, anteriores à internação: o fato de Sandrine propor que a irmã veja essas filmagens e o fato de, na sequência, vermos Sabine sendo filmada com um olhar semelhante ao que víramos das suas filmagens anteriores à internação poderiam ser também indicativos de uma extensão presente na relação dessas duas irmãs?

Originalmente, o sujeito é corpo espedaçado, coleção incoerente de desejos, mais próximo à forma do outro do que de sua própria tendência. A primeira síntese egoica é alienada, alter ego demonstrativo de que o eu é outro. É sobre esse centro exterior que o sujeito desejante se constitui, "em torno de um centro que é o outro na medida em que ele lhe dá a sua unidade, e o primeiro acesso que ele tem do objeto é o objeto enquanto objeto do desejo do outro" (Lacan, 1988, p. 50).
Por isso, como salientou Lacan (1988), há um momento da estruturação subjetiva em que as crianças se confundem, pois a relação narcísica é relação imaginária central para a relação inter-humana. Toda a apreensão do outro se dá por essa via, mas tal cativação é também a base da tensão agressiva, pois o eu se instaura nessa dualidade interna, "o eu é esse mestre que o sujeito encontra num outro, e que se instaura em sua função de domínio no cerne de si mesmo" (p. 110). A dialética do narcisismo mostra essa função de reflexo presente "no transitivismo infantil, no jogo de distinção em que se exerce a integração do socius... pela ação captante da imagem total no semelhante" (p. 169). Confundida com a imagem, a criança se aliena nela até considerá-la estranha e tentar separar-se de seu duplo por meio da agressividade, que tem aí função estruturante, mas que pode, em vez disso, desagregar e corroer (Lacan, 1948/1998). Afinal, nessa relação ambígua, há um eco de exclusão, pois o outro, ao mesmo tempo interior e exterior, está sempre prestes a retomar seu lugar de domínio em relação ao sujeito. $\mathrm{Na}$ economia psíquica, o ego nunca está só, comporta sempre um estranho gêmeo (eu ideal) que, no sujeito atormentado pela psicose, se torna falante. $\mathrm{O}$ eu comportará esse correlato, análogo parcial e partidário que pode proliferar em delírio. A identificação imaginária ao outro acarreta a possibilidade de fragmentação e de espedaçamento. 
Assim sendo, a relação imaginária está destinada ao conflito e à ruína, exigindo algo que se superponha a ela para manter as interações a certa distância: leis de intervalo, de suspensão de resoluções simbólicas, que inscrevem descontinuidades estruturais de uma ordem simbólica, uma determinação exterior ao ser, vinculada à inércia da linguagem.

De suas experiências, resta Sabine em um estado geral de letargia quando convocada pelo outro a compartilhar alguma atividade, como se nessa grande lentidão de movimentos restasse registrado um protesto que poderia talvez ser dito nos termos: me deixe quieta, me inclua fora dessa. Com esses momentos de ceder aos apelos do outro, em que manifesta seu constrangimento sendo praticamente arrastada pelo outro, ela alterna traços de uma agressividade que nunca é patente, mas que é direta (um tapa, um soco), mostrando desconforto ou oposição ao lugar em que é esperada.

$O$ filme permite inferir que Sandrine encarnou, no decorrer da vida de Sabine, esse lugar especular, em suplência ao lugar do Outro. Mas interessa que ela tenha insistido em ampliar esse lugar, trazendo Sabine a público, reapresentando-a ao discurso social. Mesmo que o cinema com imagens já gravadas faça tela para a cena e que a função latente do público não participe do presente da criação da cena, ele nos conduz a observações de Porge (1996) sobre o lugar estrutural do público como parte da cena na apresentação de pacientes, em que ele participa como terceiro que se interpõe na relação dual, como limite à onipotência imaginária daquele que interroga, atenuando seu efeito persecutório sobre o paciente. Entretanto, o público desse filme pode ser lugar da realização de uma intenção e, sem encarnar uma função de decifração do dizer, pode ter função de reconhecimento do dizer como possível acontecimento teatralizado - e "a teatralização é o escrito na fala” (p. 32).

\section{Para concluir}

Desde a hospitalização, Sabine pede que a porta do seu quarto seja fechada quando vai dormir. Mas, quando Sandrine lhe pergunta desde quando a porta deve ficar trancada, ela responde em um tom melódico, bem diferenciado das outras falas que são apresentadas na película: "Je... sais... plus....".

Teríamos aí, uma maneira infantil de afirmar Eu não sei mais (Je ne sais plus), no sentido de não se lembrar mais, seus motivos terem se perdido, ou tratar-se-ia de fragmentos de uma frase para sempre interrompida?

HER NAME IS SABINE... 
The movie is a chronicle of Sabine's path, sister to Sandrine, who was a psychiatric patient for a period of five years in a mental health institution. From recorded scenes of family members and sister's images made through 2006 and 2007, Sandrine shows us a narrative which bring up questions that crosses the subjects' experience in institutions and throws light on relevant points on the impact of subjective bonds into the phratry.

Index terms: transference; double; educational; transitivism; institution.

\section{ELLA SE LLAMA SABINE...}

\section{RESUMEN}

Este articulo discute algunos temas resultantes de la película documental Su nombre es Sabine (Elle s'appelle Sabine), dirigido por Sandrine Bonnaire (Francia/2007). La pelicula presenta un registro sobre el recorrido de Sabine, hermana de Sandrine, que pasó por un periodo de cinco años de internación en hospital psiquiátrico. Recortando escenas de rodajes familiares y de imágenes de la hermana captadas en los años de 2006 y 2007, Sandrine nos presenta una narrativa que permite indagar temas que atraviesan la experiencia de los sujetos en las instituciones y que hace surgir puntos importantes sobre los efectos subjetivos de los lazos que se establecen en la fratría.

Palabras clave: transmisión; doble; transitivismo; educacional; institución.

\section{REFERÊNCIAS}

Bonnaire, S. (Diretor). (2007). O nome dela é Sabine. [filme-documentário]. Paris, França: Mosaïque Films. (Título original: Elle s’appelle Sabine)

Dorey, R. (1996). A favor da apresentação clínica. Boletim de Novidades da Pulsional, 87 (IX), 5-18.

Faivre-Jussiaux M. (1995). L'enfant lumiére. Paris: Payot \& Rivages.

Freud, S. (1977a). Extratos das notas de rodapé de Freud: a sua tradução de Leçons du mardi, de Charcot. In S. Freud, Edição standard brasileira das obras psicológicas completas de Sigmund Freud (J. Salomão, trad., Vol. 1, pp. 25-30). Rio de Janeiro: Imago. (Trabalho original publicado em 1892)

Freud, S. (1977b). Um estudo autobiográfico. In S. Freud, Edição standard brasileira das obras psicológicas completas de Sigmund Freud (J. Salomão, trad., Vol. 20, pp.17-92). Rio de Janeiro: Imago. (Trabalho original publicado em 1925)

Freud, S. (1977c). Os chistes e sua relação com o inconsciente. In S. Freud, Edição standard brasileira das obras psicológicas completas de Sigmund Freud (J. Salomão, trad., Vol. 8, pp. 21-290). Rio de Janeiro: Imago. (Trabalho original publicado em 1905)

Freud, S. (1977d). Tipos psicopáticos no palco. In S. Freud, Edição standard brasileira das obras psicológicas completas de Sigmund Freud (J. Salomão, trad., Vol. 7, pp. 321327). Rio de Janeiro: Imago. (Trabalho original publicado em 1906)

Freud, S. (1977e). A interpretação dos sonhos. In S. Freud, Edição standard brasileira das obras psicológicas completas de Sigmund Freud (J. Salomão, trad., Vol. 5, pp. 361793). Rio de Janeiro: Imago. (Trabalho original publicado em 1900)

Hanns, L (1996). Dicionário comentado do alemão de Freud. Imago: Rio de Janeiro. 
Itard J. (2000). Relatório I: Da educação de um homem selvagem ou dos primeiros desenvolvimentos físicos e morais do jovem Selvagem do Aveyron. In L. Banks -Leite \& I. Galvão (Orgs.), A educação de um selvagem: as experiências pedagógicas de Jean Itard (pp. 123-177). São Paulo: Cortez. (Trabalho original publicado em 1801)

Lacan, J. (1998). A agressividade em psicanálise. In J. Lacan, Escritos (pp.104-126). Rio de Janeiro: Jorge Zahar. (Trabalho original publicado em 1948)

Lacan, J. (1985). O seminário, livro 2: o eu na teoria de Freud e na técnica da psicanálise, 1954-1955. Rio de Janeiro: Jorge Zahar. (Trabalho original publicado em 1978)

Lacan, J. (1988). O seminário, livro 3: as psicoses, 1955-1956. Rio de Janeiro: Jorge Zahar. (Trabalho original publicado em 1981)

Laurent, E. (2008). Uma psicanálise orientada para o real. Carretel: Psicoanálisis con Niños, 8, 39-48. Recuperado em 6 de janeiro, 2013, de http://www.institutopsicanalise-mg.com.br.

Plaisance, É. (2000). Les mots de l'éducation spéciale. In M.Chauvière \& É. Plaisance (sous la direction de), L'école face aux handicaps: éducation spéciale on éducation intégrative? (pp. 16-29). Paris: PUF.

Porge, É. (1996). A apresentação de doentes. Revista Pulsional, 87, 19-40.

Reliquet, S., \& Relique, P. (2011). Écouter Handel. Paris: Gallimard.

Vives, J.-M. (2012). A voz na clínica psicanalítica. Rio de Janeiro: Contra Capa.

Vorcaro, A., \& Rahme. M. (2011). Interrogações sobre o estatuto do outro e do Outro nos autismos. Associação Psicanalitica de Curitiba em Revista, 22, 29-52.

Vorcaro A., \& Veras, V. (2008). O brincar como operação de escrita. Revista Estilos da Clínica: Revista sobre a Infância com Problemas, 24 (13), 24-39.

\section{NOTAS}

1. O filme é apresentado pela primeira vez no Festival de Cannes, em maio de 2007, quando obtém o Prêmio Fipreschi da crítica internacional. Em 2008 é exibido pelo canal France3 e recebe o prêmio de Melhor Primeiro Filme, concedido pelo Sindicato Francês da Crítica de Cinema. No ano de 2009 é indicado para o César, na categoria de melhor filme documentário.

Ficha técnica:

Título original: Elle s'appelle Sabine/França/2007

Gênero: documentário

Duração: 85 min.

Direção: Sandrine Bonnaire

O filme é apresentado pela primeira vez no Festival de Cannes, em maio de 2007, quando obtém o Prêmio Fipreschi da crítica internacional. Em 2008 é exibido pelo canal France3 e recebe o prêmio de Melhor Primeiro Filme, concedido pelo Sindicato Francês da Crítica de Cinema. No ano de 2009 é indicado para o César, na categoria de melhor filme documentário.

2. Darstellung e Darstellbarkeit foram traduzidas como "figura" e "figurabilidade", respectivamente. O advérbio da ("aí", "então", "naquele momento", "na medida em que"), condensando espaço e tempo na causalidade da narrativa, articula-se a Stellen ("colocar em pé", "armar", "pôr em condições de funcionar") para formar Darstellen ("colocar diante dos olhos", "mostrar publicamente", "constituir", "colocar 
em forma sensorialmente apreensível"), tendo caráter intersubjetivo por visar ao outro. Difere, portanto, de representação. Figurabilidade seria uma exprimibilidade em imagens. Nos sonhos, a figurabilidade refere-se às possibilidades de um conteúdo ser colocado em linguagem e mostrado (Hanns, 1996, p. 381). Figurabilidade, ligada ao processo de deslocamento, produz também a desfiguração (Vorcaro \& Veras, 2008).

angelavorcaro@uol.com.br

Rua Paul Bouthilier, 353

30315-010 - Belo Horizonte - MG - Brasil.

monicarahme@hotmail.com

Rua do Seminário s/n

35420-000 - Mariana - MG - Brasil.

Recebido em fevereiro/ 2013.

Aceito em abril/2013. 